\title{
The Prevention of Gestational Diabetes
}

\section{Emilio Giugliano ${ }^{1 *}$, Elisa Cagnazzo ${ }^{1}$, Brunella Giugliano ${ }^{1}$, Donatella Caserta ${ }^{2}$, Massimo Moscarini ${ }^{2}$ and Roberto Marci ${ }^{1}$}

${ }^{1}$ Department of Morphology, Surgery and Experimental Medicine, Section of Obstetrics and Gynecology, University of Ferrara, Italy ${ }^{2}$ Department of Woman's Health and Territorial Medicine, Faculty of Medicine and Psychology, University of Rome La Sapienza, Italy

\begin{abstract}
The negative impact of the gestational diabetes on the maternal and fetal health is well known and this impact is closely related to gestational age at which the diagnosis is done. Therefore, the use of therapeutic options able to prevent or delay the gestational diabetes occurrence has a positive impact on maternal and neonatal outcomes.

Physical activity and dietary advice represent the first choice and they are the most studied as well. They represent a non-pharmacological option and have a positive impact on insulin resistance although they do not seem to prevent the gestational diabetes onset.The preconceptional use of metformin in women with polycystic ovary syndrome protects the pancreatic beta cell reserve preventing or delaying the occurrence of gestational diabetes. However, there are also doubts on the drug safety in pregnancy since it completely crosses the placenta.From this point of view, the inositol could represent an excellent alternative.lts role as insulin sensitizing agent is well documented on improving both the hormonal and reproductive parameters. However, the studies on its preconceptional use in preventing gestational diabetes are too limited though the first results are extremely encouraging.
\end{abstract}

Keywords: Diabetes mellitus; Exercise therapy; Gestational diabetes; Inositol; Metformin

\section{Introduction}

Pregnancy increases requirements for insulin secretion while increasing insulin resistance (IR) [1], increasing demands on pancreatic beta cells [2], in presence of impaired pancreatic beta-cell compensation for IR [3], and leads to gestational diabetes mellitus (GDM) [4].

GDMis associated to risks for the fetus, including macrosomia and birth injuries for shoulder dystocia, for the newborn such as neonatal hypoglycemia, respiratory distress syndrome, childhood obesity, and for the mother, such as caesarean delivery, hypertensive disorders and an increased risk of developing type 2 diabetes later in life $[5,6]$. The US Preventative Services Task Force recently concluded that screening for GDM in all pregnant women cannot be justified [7], although two recent randomized controlled trials have demonstrated improved outcomes of neonates in GDM pregnancy whose mothers were treated with diet and/or insulin, compared with no treatment $[8,9]$.

Therefore, the prevention of GDM is of paramount importance in order to reduce deleterious effects on women's long-term health and their offspring as much as possible. For this purpose, several strategies have been proposed to prevent GDM over the years such as exercise, weight loss, oral hypoglycemic [10,11].

Considering the insulin-mimetic effect of inositol supplementation in several animal models of insulin resistance [12-14] and in women with polycystic ovary syndrome (PCOS) [15], it has been recently hypothesized and studied its positive on the GDM incidence [16-19].

The aim of this review is to discuss several options to prevent GDM occurrence, paying attention on the potential role of a dietary inositol supplement.

\section{GDM-Related Perinatal Complications}

Women with GDM have an increased incidence of hypertensive disorders during pregnancy; in particular the incidence for chronic hypertension varies between $2.5-5 \%$, for pre-eclampsia between $5-15 \%$ and for gestational hypertension is approximately $6 \%[8,20,21]$. These clinical conditions may partially explain the association between GDM and preterm delivery. Indeed, in the HAPO study approximately 1608 of the 23316 patients $(6.9 \%)$ experienced preterm delivery although it had minimal association with fasting glucose levels [22]. Regarding the risk of shoulder dystocia, it increases with obesity and additionally with GDM. In HAPO study, it was one of the least common outcomes, with only $1.3 \%$ of the women affected [22]. The increased risk conferred by GDM is thought to be related to anthropometric abnormalities in GDM infants. The risk of stillbirth was also increased before the advent of GDM treatment. However, note that in more recent years and in industrialized nations, stillbirth is an uncommon outcome.

To reduce these complications related to GDM, Caesarean delivery has been successfully employed. In HAPO study, $16 \%$ of women with GDM underwent primary caesarean section (CS). Moreover, elevated fasting glucose, 1-hour glucose and 2-hour glucose were all associated with increased odds of primary CS [22]. GDM may also affect health newborn: maternal hyperglycemia is thought to lead to excess fetal glucose exposure and fetal hyperinsulinemia [23]. In turn, fetal hyperinsulinemia is thought to lead to hyperplasia of fat tissue, skeletal muscle, and subsequent neonatal hypoglycemia [23]. Another GDM effect on newborn health is hyperbilirubinemia. Maternal hyperglycemia and the subsequent induction of fetal hyperinsulinemia are hypothesized to lead to increased fetal oxygen uptake, fetal erythropoiesis, and subsequent hyperbilirubinemia [24].

GDM may also cause long-term complicationsfor both mother and infant. There are several hypotheses postulatingpermanent changes in

*Corresponding author: Emilio Giugliano, Department of Morphology, Surgery and Experimental Medicine, Section of Obstetrics and Gynecology, University of Ferrara, CorsoGiovecca 203, Ferrara, Italy 44121, Tel: +390532236297; Fax: +390532203844; E-mail: doctorgiugli@hotmail.it

Received July 24, 2013; Accepted August 21, 2013; Published August 26, 2013

Citation: Giugliano E, Cagnazzo E, Giugliano B, Caserta D, Moscarini M, et al. (2013) The Prevention of Gestational Diabetes. J Diabetes Metab 4: 286 doi:10.4172/2155-6156.1000286

Copyright: (c) 2013 Giugliano E, et al. This is an open-access article distributed under the terms of the Creative Commons Attribution License, which permits unrestricted use, distribution, and reproduction in any medium, provided the original author and source are credited. 
fetal metabolism during theintrauterine exposure to hyperglycemia. During GDM pregnancy, the fetus may be imprinted or programmed, resulting in excess fetal growth, decreased insulin sensitivity, and impaired insulin secretion. These changes may be associated with impaired glucose tolerance during early youth and adolescence [2527]. Moreover, GDM may cause a reduced pancreatic beta-cell reserve in the mother that can manifest in the decade after delivery with the onset diabetes mellitus [28]. Even among women who have a normal postpartum glucose tolerance test, the risk of future diabetes may be up to seven-fold higher than in women without histories of GDM [29].

\section{Strategies for Prevention of GDM}

One important physiological change that occurs in normal pregnancies is a progressive increase in IR at the muscle level [30]. This normal IR reduces the maternal uptake of glucose concentrations to ensure an adequate glucose supply for fetal growth and development [30]. The deterioration of this physiological metabolic change causes the continuous pancreatic beta-cell insufficiency so that GDM may develop.

Interventionsimproving glucose tolerance by attenuating pregnancy-induced IR or by achieving glycemic control may help in preventing GDM.

\section{Physical activity}

Regular physical activity in non-pregnant individuals results in numerous health benefits, such as, improvements in glucose homeostasis and insulin sensitivity [31-33]. These beneficial effects of physical activity are due, in part, to an increased responsiveness of muscle uptake to insulin related to an increase in GLUT-4 expression [34,35].

Pregnancy-induced IR develops at the skeletal muscle level [30] and it is likely that the physiological and molecular mechanisms underlying the beneficial effects of physical activity in non pregnant population may also be present in pregnant women. In this regard, different studies have been carried out over the years and recently published systematic reviews and meta-analyses showed that prenatal activity has no effect on the prevention of GDM [36-38].

However, the lack of consistent evidence regarding the benefits of exercise could be due to several factors, such as the small sample size, the study design, the method to assess glucose tolerance/insulin sensitivity or the compliance of the women with the interventions. The latter has been found to be a major problem; factors such as concerns for the safety of the baby, physical limitations, and lack of energy, motivation or resources may contribute to the low compliance with the exercise recommendations. Therefore, some authors proposed supervised exercise sessions in order to favor patients' compliance even though nobeneficial results have been reported yet $[39,40]$. Lifestyle interventions combining physical activity and nutrition have been found to be more effective than physical activity interventions alone in limiting gestational weight gain [41].

However, it has not been demonstrated a direct linkbetween limiting gestational weight gain and prevention of GDM; physical activity-based interventions may influence glucose and insulin metabolism without affecting gestational weight gain [42-44], supporting the independent effect of exercise on glucose and insulin metabolism regulation via its direct effect on skeletal muscle cell adaptations $[34,35]$.

Taken together, the different characteristics of the studies make difficult their comparison. The limited evidence from physical activity- based interventions suggests that in order to be more successful in preventing the deterioration of glucose tolerance and insulin sensitivity, pregnant women should engage in regular physical activity at least three times per week at moderate intensity for 30 minutes or more [42-47]. However, since glucose response to exercise is influenced by several factors, such as exercise modality, duration, and intensity [4850], further research is needed.

\section{Dietary advice}

Glucose is the primary source of energy for fetal growth [51]. The aim of dietary advice is to prevent maternal hyperglycemia attenuating the IR of the pregnancy so as to prevent the onset of GDM. These dietary recommendations are based on a single benchmark representing by glycemic index (GI). It provides a measure of how quickly blood sugar levels rise after eating a particular type of food [52] since low glycemic index diets have shown to benefit those being treated for diabetes [53]. Several authors compared different food programs during pregnancy based on high or low GI. The dietary intervention generally began during the first trimester; thirty per cent of total energy intake was to be fat and $55 \%$ carbohydrate food.

These different dietary recommendations had a beneficial maternal and neonatal impact. Women with the low GI diet were to be at decreased risk of having large-for-gestational-age infants. Moreover, babies born to mothers on the low GI diet were significantly lighter and had significantly lower ponderal indexes than babies born to mothers on the high GI diet $[54,55]$. The impact of the low GI diet preventing GDM was highlighted by maternal fasting blood glucose that was significantly lower. Despite the different dietary regimens, patient's compliance was unchanged, thus the authors reported no significant difference in acceptability and affordability of the low and high GI diets [56].

These results are promising; however need to say that the number of trial is limited. We have to highlight that the low GI diet has several beneficial effects on both fetus and mother but it is necessary a large sample size to demonstrate that the dietary recommendations may prevent GDM. The evidence of reduced fasting blood glucosein women with low GI diet is cheering; however another maternal outcome should be studied to reveal a decreased incidence of GDM.

\section{Metformin}

Metformin is a drug widely studied in women with PCOS, able to restore ovulation and reduce the incidence of pregnancy loss [57]. However, its insulin-sensitizing action seems not only to improve the female fertility but also to prevent the GDM. Several authors proposed that metformin protects pancreatic beta cell's reserve reducing the secretory demands imposed by chronic IR and this could slow or stop progression of subsequent type 2 diabetes mellitus (DM2) [58,59]. This physiological mechanism has been proposed to explain the interesting results of several studies over the years [60-64]. The authors demonstrated the decreased incidence of GDM and a better glycemic control throughout pregnancy by the preconception metformin supplementation in PCOS patients. Nevertheless, remains to be verified the effect of metformin on perinatal complications by GDM such as preterm delivery and preeclampsia $[65,66]$. Moreover, the major doubt related to metformin use during pregnancy concerns the possible perinatal complications. Indeed, metformin easily crosses the placenta so the fetus is exposed to drug concentrations comparable with those of the mother [67]. Although recent studies with larger populations 
support the safety of metformin during pregnancy [68,69], the lack of data on long-term perinatal complications requires some caution.

\section{Inositol}

Inositol is a cyclitol naturally present in animal and plant cells, either in its free form or as a bound-component of phospholipids or inositol derivates. It plays an important role in various cellular processes as the structural basis for secondary messengers in eukaryotic cells $[70,71]$.

It exists under nine stereoisomeric forms depending on the spatial orientation of its six hydroxyl groups. Myo-inositol (MI) is the predominant isomeric form and is considered to belong to the vitamin B family. The conversion of MI in d-chiro-inositol (DCI) can occur in tissues expressing the specific epimerase. Pak et al. measured a conversion rate of $\mathrm{MI}$ to DCI of about $7.6 \%$ in rat blood and $8,8 \%$ in rat muscle and liver [72].

\section{Inositol and insulin resistance}

Abnormalities in MI and DCI metabolism have been involved in the development of several diseases and in particular in the development of IR and diabetic complications. Indeed, a depletion of MI intracellular is commonly observed in primary sites for development of diabetic microvascular complications (kidney, sciatic nerve, retina and lens) in diabetic animal models and human subjects $[73,74]$. Inhibition of cellular MI uptake, altered MI biosynthesis and increased MI degradation are putative mechanisms of MI depletion [75]. It could have a negative impact on the synthesis and availability of phosphatidylinositol (PI) in the cells. Indeed, altered PI metabolism associated to MI deficiency has been observed in the sciatic nerve of diabetic rat model [76].

The conversion of MI-DCI also seems to be altered in insulinresistant patients. Larner et al. described a decreased urinary excretion of DCI and an increased urinary excretion of MI in human subjects and rhesus monkey with DM2 [73]. In monkeys the inositol excretion pattern became more marked with the progression of the diabetic disease and additional studies demonstrated that this altered inositol profile in urine is more directly related to the underlying IR so much so that the altered ratios of increased MI to decreased DCI in urine have been proposed as index of IR in human [12,77]. A defect in MI to DCI epimerization activity was demonstrated in vivo in rats and in vitro in fibroblasts to explain this inositol imbalance $[72,78]$.

The consequence of this altered mechanism is that the excessive urinary MI excretion reduces MI plasma level and consequently emphasizes MI intracellular depletion. Decreased production of DCI from MI reduces the availability of intracellular DCI for its incorporation in inositol phosphoglycans (IPGs), putative second messenger of insulin. Therefore, the decreased DCI content in insulin target tissues could reduce insulin signal transduction and contribute to the IR [79]. Therefore, it seems reasonable to speculate on a possible effect of MI and/or DCI supplementation in insulin-resistant patients to prevent GDM.

Moreover, the importance of inositol metabolism has been recently reinforced by other Authors those founda higher amounts of MI in the urine of intrauterine growth restriction birth compared to control infants [80]. These findings require careful reflection on their meaning.

\section{Inositol in human reproduction}

The impact of inositol supplementation on the IR has been proved in vivo so that is one of the most used insulin-sensitizing agents to restore spontaneous ovarian activity in women with PCOS [15]. The beneficial effects of inositol have been also proved on metabolic and hormonal parameters in insulin-resistant women. Indeed, a significant improvement of typical hormonal parameters was observed in PCOS women after MI treatment: decreased $\mathrm{LH}, \mathrm{FSH}$, and testosterone circulation levels, and increased SHBG, estrogens and progesterone circulating levels [81-83]. Insulin peripheral sensitivity was improved(reduced HOMA-IR index and/or reduction of the AUC of glucose and insulin during an oral glucose tolerance test) as well as markers of cardiovascular risk with a decrement in systolic and diastolic blood pressure, a decrease in plasma triglycerides, an increased in HDL cholesterol, and a decrease in LDL and total cholesterol concentrations $[84,85]$. These results have incremented the research in the field of human reproduction so that MI supplementation was tested in patients undergoing multiple follicular stimulationsfor IVF [86,87].

Therefore, given the wide use of inositol in infertile patients at risk for GDM (women with PCOS), some authors have recently tested the effect of preconceptional inositol supplementation on the GDM onset.

\section{Inositol as a therapeutic option to prevent GDM}

The good findings of MI supplementation on the IR have been confirmed also in the patients with GDM. In particular, Corrado et al. found a decreased fasting glucose and insulin in GDM patients treated by $4 \mathrm{~g}$ MI daily [16]. Afterwards, D'Anna et al. have published the first report about the effect of MI on GDM occurrence in PCOS infertile women [17].

The authors have retrospectively considered 98 anovulatory and hyperinsulinemic PCOS non diabetic patients achieving spontaneous pregnancy after treatment with MI plus folic acid (n.54) throughout the whole pregnancy, or with metformin (n. 44) until a positive pregnancy test occurred. The difference of GDM occurrence comparing the groups was highly significant ( $17 \%$ vs. $54 \%$; $p<0.001)$, showing a double risk of GDM in the control group (OR: 2.4; CI 95\% 1.3-4.4) compared to the MI group. Despite the limited number of study population, the authors highlighted the significant trend in favor of the MI group even though they stated the need to confirm these results on a larger number of patients. Indeed, the same authors published subsequently the results of a prospective, randomized, placebo-controlled study [18]. They enrolled 220 pregnant outpatients witha parent DM2 randomizing them in two groups: 110 patients treated from the end of the first trimester with $2 \mathrm{~g}$ MI plus $200 \mu \mathrm{g}$ folic acid twice a day (treated group) and 110 patients only treated with $200 \mu \mathrm{g}$ folic acid twice a day (control group) through the whole pregnancy. The prevalence of GDM was significantly reduced in the treated group ( 6 vs. $15 \%$ ), and a reduction of $65 \%$ of the risk for GDM (OR 0.35; CI 95\% 0,13-0,96) was registered. A significant difference was also highlighted in glycaemia at the OGTT either at basal values $(\mathrm{p}<0.001)$ or in the first hour $(\mathrm{p}<0.02)$. Furthermore, a statistically significant reduction of fetal macrosomia $(p<0.007)$ in the treated group was also highlighted together with a significant reduction in mean fetal weight at delivery $(\mathrm{p}<0.01)$.

Also Matarrelli et al. found similar results conducting a prospective, randomized, double-blinded, placebo-controlled clinical trial [19]. They enrolled 84 non-obese singleton pregnant women with an elevated fasting glucose in the first or early second trimester randomizing them to receive either MI or placebo. The group of women allocated to receive MI had a significantly lower incidence of abnormal OGTT (71 vs. $6 \%$; OR 0.12, CI 95\% 0.03-0.5). Basal, 1 and 2 hour glycemic controls were significantly lower in the MI group $(\mathrm{p}<0.001,<0.04,0.06$, respectively). 
Furthermore, after birth, neonatal hypoglycemia was significantly lower in MI group (0 vs. 26\%, OR: 0.05, CI 95 0.003-0.849).

Despite these three studies are different for design and study population, they agreed in emphasizing the effect of MI to reduce the incidence of GDM. Although these studies are based on a small sample size, the positive trend in favor of MI supplementation is evident. It is also confirmed by secondary measured outcomes as neonatal hypoglycemia, fetal macrosomia or glycaemia at OGTT whose incidence was significantly lower in the treated groups.

\section{Conclusions}

The negative impact of the GDM on the maternal and fetal health is well known. This impact is closely related to gestational age at which the diagnosis of GDM is done. Therefore, the use of therapeutic options able to prevent or delay the GDM occurrence has a positive impact on maternal and neonatal outcomes.

Physical activity and dietary advice represent the first choice and they are the most studied as well. They represent a non-pharmacological option and have a positive impact on insulin resistance although they do not seem to prevent the GDM onset. Moreover, the insufficient compliance of the patient very often represents a limiting factor.

On the contrary, the role of hypoglycemic agent as metformin is well known in the management and treatment of GDM. The preconceptional use of metformin in PCOS women protects the pancreatic beta cell reserve preventing or delaying the occurrence of GDM. However, there are also doubts on the drug safety in pregnancy since it completely crosses the placenta. Several authors demonstrated the perinatal safety of the drug but larger studies are needed. From this point of view, the inositol could represent an excellent alternative. It is normally present in the human organism (so it could be used safely in pregnancy) and its depletion is closely related to the insulin resistance. Its role as insulin sensitizing agent is well documented on improving both the hormonal and reproductive parameters. However, the studies on its preconceptional use in preventingGDM are too limited. The first results are extremely encouraging showing lower incidence of GDM in the women treated with $4 \mathrm{~g} /$ die of MI. To confirm this positive trend, it would be interesting to study the impact of inositol on secondary outcomes as fetal macrosomia, gestational hypertension, pre-eclampsia, preterm birth. In this way, we could really confirm that the MI supplementation has a positive overall effect on the maternal health. Furthermore, confirming these data on a larger sample size could represent the first step in the discovery of an important and validated non-pharmacological option to prevent GDM.

\section{References}

1. Homko C, Sivan E, Chen X, Reece EA, Boden G (2001) Insulin secretion during and after pregnancy in patients with gestational diabetes mellitus. J Clin Endocrinol Metab 86: 568-573.

2. Butte NF (2000) Carbohydrate and lipid metabolism in pregnancy: normal compared with gestational diabetes mellitus. Am J Clin Nutr 71: 1256S-61S.

3. Xiang AH, Peters RK, Trigo E, Kjos SL, Lee WP, et al. (1999) Multiple metabolic defects during late pregnancy in women at high risk for type 2 diabetes. Diabetes 48: 848-854.

4. Buchanan TA, Xiang AH, Peters RK, Kjos SL, Berkowitz K, et al. (2000) Response of pancreatic beta-cells to improved insulin sensitivity in women at high risk for type 2 diabetes. Diabetes 49: 782-788.

5. Dennedy MC, Dunne F (2010) The maternal and fetal impacts of obesity and gestational diabetes on pregnancy outcome. Best Pract Res Clin Endocrinol Metab 24: 573-589.

6. Hawdon JM (2011) Babies born after diabetes in pregnancy: what are the short- and long-term risks and how can we minimise them? Best Pract Res Clin Obstet Gynaecol 25: 91-104.

7. Hillier TA, Vesco KK, Pedula KL, Beil TL, Whitlock EP, et al. (2008) Screening for gestational diabetes mellitus: a systematic review for the U.S. Preventive Services Task Force. Ann Intern Med 148: 766-775.

8. Crowther CA, Hiller JE, Moss JR, McPhee AJ, Jeffries WS, et al. (2005) Effect of treatment of gestational diabetes mellitus on pregnancy outcomes. $\mathrm{N}$ Engl J Med 352: 2477-2486.

9. Landon MB, Spong CY, Thom E, Carpenter MW, Ramin SM, et al. (2009) A multicenter, randomized trial of treatment for mild gestational diabetes. $\mathrm{N}$ Eng J Med 361: 1339-1348.

10. Ruchat SM, Mottola MF (2013) The important role of physical activity in the prevention and management of gestational diabetes mellitus. Diabetes Metab Res Rev 29: 334-346.

11. Ratner RE, Christophi CA, Metzger BE, Dabelea D, Bennett PH, et al. (2008) Prevention of diabetes in women with a history of gestational diabetes: effects of metformin and lifestyle interventions. J Clin Endocrinol Metab 93: 4774-4779.

12. Ortmeyer HK, Huang LC, Zhang L, Hansen BC, Larner J (1993) Chiroinositol deficiency and insulin resistance. II. Acute effects of D-chiroinosito administration in streptozotocin-diabetic rats, normal rats given a glucose load, and spontaneously insulin-resistant rhesus monkeys. Endocrinology 132: 646651

13. Ortmeyer HK (1996) Dietary myoinositol results in lower urine glucose and in lower postprandial plasma glucose in obese insulin resistant rhesus monkeys. Obes Res 4: 569-575.

14. Ortmeyer HK, Larner J, Hansen BC (1995) Effects of D-chiroinositol added to a meal on plasma glucose and insulin in hyperinsulinemic rhesus monkeys Obes Res 3: 605S-608S

15. Unfer V, Carlomagno G, Dante G, Facchinetti F (2012) Effects of myo-inosito in women with PCOS: a systematic review of randomized controlled trials Gynecol Endocrinol 28: 509-515.

16. Corrado F, D'Anna R, Di Vieste G, Giordano D, Pintaudi B, et al. (2011) The effect of myoinositol supplementation on insulin resistance in patients with gestational diabetes. Diabet Med 28: 972-975.

17. D'Anna R, Di Benedetto V, Rizzo P, Raffone E, Interdonato ML, et al (2012) Myo-inositol may prevent gestational diabetes in PCOS women. Gynecol Endocrinol 28: 440-442.

18. D'Anna R, Scilipoti A, Giordano D, Caruso C, Cannata ML, et al. (2013) myoInositol supplementation and onset of gestational diabetes mellitus in pregnan women with a family history of type 2 diabetes: a prospective, randomized, placebo-controlled study. Diabetes Care 36: 854-857.

19. Matarrelli B, Vitacolonna E, D'angelo M, Pavone G, Mattei PA, et al. (2013) Effect of dietary myo-inositol supplementation in pregnancy on the incidence of maternal gestational diabetes mellitus and fetal outcomes: a randomized controlled trial. J Matern Fetal Neonatal Med 26: 967-972.

20. Hadden DR (1998) A historical perspective on gestational diabetes. Diabetes Care 21: B3-4

21. Yogev, Chen, Hod, Coustan, Oats, et al. (2010) Hyperglycemia and Adverse Pregnancy Outcome (HAPO) study: preeclampsia. Am J Obstet Gynecol 202 255.

22. HAPO Study Cooperative Research Group, Metzger BE, Lowe LP, Dyer AR Trimble ER, et al. (2008) Hyperglycemia and adverse pregnancy outcomes. N Engl J Med 358: 1991-2002.

23. McIntyre HD, Chang AM, Callaway LK, Cowley DM, Dyer AR, et al. (2010) Hormonal and metabolic factors associated with variations in insulin sensitivity in human pregnancy. Diabetes Care 33: 356-360.

24. Ferrara A, Weiss NS, Hedderson MM, Quesenberry CP Jr, Selby JV, et al. (2007) Pregnancy plasma glucose levels exceeding the American Diabetes Association thresholds, but below the National Diabetes Data Group thresholds for gestational diabetes mellitus, are related to the risk of neonatal macrosomia, hypoglycaemia and hyperbilirubinaemia. Diabetologia 50: 298-306.

25. Pedersen J (1954) Weight and length at birth of infants of diabetic mothers Acta Endocrinol (Copenh) 16: 330-342.

26. Catalano PM, Thomas A, Huston-Presley L, Amini SB (2003) Increased fetal adiposity: a very sensitive marker of abnormal in utero development. Am J Obstet Gynecol 189: 1698-1704. 
27. Catalano PM, Kirwan JP, Haugel-de Mouzon S, King J (2003) Gestational diabetes and insulin resistance: role in short- and long-term implications for mother and fetus. J Nutr 133: 1674S-1683S

28. Kim C, Newton KM, Knopp RH (2002) Gestational diabetes and the incidence of type 2 diabetes: a systematic review. Diabetes Care 25: 1862-1868.

29. Bellamy L, Casas JP, Hingorani AD, Williams D (2009) Type 2 diabetes mellitus after gestational diabetes: a systematic review and meta-analysis. Lancet 373 : 1773-1779.

30. Buchanan TA, Xiang AH (2005) Gestational diabetes mellitus. J Clin Invest 115: $485-491$.

31. Goodyear LJ, Kahn BB (1998) Exercise, glucose transport, and insulin sensitivity. Annu Rev Med 49: 235-261.

32. Madden SG, Loeb SJ, Smith CA (2008) An integrative literature review of lifestyle interventions for the prevention of type II diabetes mellitus. J Clin Nurs 17: 2243-2256.

33. Yates T, Khunti K, Bull F, Gorely T, Davies MJ (2007) The role of physical activity in the management of impaired glucose tolerance: a systematic review. Diabetologia 50: 1116-1126.

34. Hayashi T, Wojtaszewski JF, Goodyear LJ (1997) Exercise regulation of glucose transport in skeletal muscle. Am J Physiol 273: E1039-1051.

35. Ryder JW, Chibalin AV, Zierath JR (2001) Intracellular mechanisms underlying increases in glucose uptake in response to insulin or exercise in skeletal muscle. Acta Physiol Scand 171: 249-257.

36. Han S, Middleton P, Crowther CA (2012) Exercise for pregnant women for preventing gestational diabetes mellitus. Cochrane Database Syst Rev 7 : CD009021.

37. Oostdam N, van Poppel MN, Wouters MG, van Mechelen W (2011) Interventions for preventing gestational diabetes mellitus: a systematic review and meta-analysis. J Womens Health (Larchmt) 20: 1551-1563.

38. Thangaratinam S, Rogozinska E, Jolly K, Glinkowski S, Duda W, et al. (2012) Interventions to reduce or prevent obesity in pregnant women: a systematic review. Health Technol Assess 16: iii-iv, 1-191.

39. Oostdam N, van Poppel MN, Wouters MG, Eekhoff EM, Bekedam DJ, et al (2012) No effect of the FitFor2 exercise programme on blood glucose, insulin sensitivity, and birthweight in pregnant women who were overweight and at risk for gestational diabetes: results of a randomised controlled trial. BJOG 119 : 1098-1107.

40. Stafne SN, Salvesen KÅ, Romundstad PR, Eggebø TM, Carlsen SM, et al. (2012) Regular exercise during pregnancy to prevent gestational diabetes: a randomized controlled trial. Obstet Gynecol 119: 29-36.

41. Streuling I, Beyerlein A, von Kries R (2010) Can gestational weight gain be modified by increasing physical activity and diet counseling? A meta-analysis of interventional trials. Am J Clin Nutr 92: 678-687.

42. Callaway LK, Colditz PB, Byrne NM, Lingwood BE, Rowlands IJ, et al. (2010) Prevention of gestational diabetes: feasibility issues for an exercise intervention in obese pregnant women. Diabetes Care 33: 1457-1459.

43. Ong MJ, Guelfi KJ, Hunter T, Wallman KE, Fournier PA, et al. (2009) Supervised home-based exercise may attenuate the decline of glucose tolerance in obese pregnant women. Diabetes Metab 35: 418-421.

44. van Poppel MN, Oostdam N, Eekhoff ME, Wouters MG, van Mechelen W, et al. (2013) Longitudinal relationship of physical activity with insulin sensitivity in overweight and obese pregnant women. J Clin Endocrinol Metab 98: 29292935.

45. Barakat R, Cordero Y, Coteron J, Luaces M, Montejo R (2012) Exercise during pregnancy improves maternal glucose screen at 24-28 weeks: a randomised controlled trial. Br J Sports Med 46: 656-661.

46. ACOG Committee Obstetric Practice (2002) ACOG Committee opinion Number 267, January 2002: exercise during pregnancy and the postpartum period. Obstet Gynecol 99: 171-173.

47. Davies GA, Wolfe LA, Mottola MF, MacKinnon C; Society of Obstetricians and gynecologists of Canada, SOGC Clinical Practice Obstetrics Committee (2003) Joint SOGC/CSEP clinical practice guideline: exercise in pregnancy and the postpartum period. Can J Appl Physiol 28: 330-341.

48. Ruchat SM, Davenport MH, Giroux I, Hillier M, Batada A, et al. (2012) Effect of exercise intensity and duration on capillary glucose responses in pregnant women at low and high risk for gestational diabetes. Diabetes Metab Res Rev 28: 669-678.

49. Bessinger RC, McMurray RG (2003) Substrate utilization and hormona responses to exercise in pregnancy. Clin Obstet Gynecol 46: 467-478.

50. Clapp JF (2006) Effects of Diet and Exercise on Insulin Resistance during Pregnancy. Metab Syndr Relat Disord 4: 84-90.

51. Moses RG, Brand-Miller JC (2011) The use of a low glycaemic index diet in pregnancy: an evolving treatment paradigm. Diabetes Res Clin Pract 91: 13-14.

52. Foster-Powell K, Holt SH, Brand-Miller JC (2002) International table of glycemic index and glycemic load values: 2002. Am J Clin Nutr 76: 5-56.

53. Louie JC, Markovic TP, Perera N, Foote D, Petocz P, et al. (2011) A randomized controlled trial investigating the effects of a low-glycemic index die on pregnancy outcomes in gestational diabetes mellitus. Diabetes Care 34 2341-2346.

54. Moses RG, Luebcke M, Davis WS, Coleman KJ, Tapsell LC, et al. (2006) Effect of a low-glycemic-index diet during pregnancy on obstetric outcomes. Am J Clin Nutr 84: 807-812.

55. Clapp JF 3rd (2002) Maternal carbohydrate intake and pregnancy outcome. Proc Nutr Soc 61: 45-50.

56. Farrar D, Duley L, Lawlor DA (2011) Different strategies for diagnosing gestational diabetes to improve maternal and infant health. Cochrane Database Syst Rev : CD007122.

57. Xiao J, Chen S, Zhang C, Chang S (2012) The effectiveness of metformin ovulation induction treatment in patients with PCOS: a systematic review and meta-analysis. Gynecol Endocrinol 28: 956-960.

58. Buchanan TA (2003) Pancreatic beta-cell loss and preservation in type 2 diabetes. Clin Ther 25: B32-46.

59. Glueck CJ, Goldenberg N, Wang P, Loftspring M, Sherman A (2004) Metformin during pregnancy reduces insulin, insulin resistance, insulin secretion, weight, testosterone and development of gestational diabetes: prospective longitudinal assessment of women with polycystic ovary syndrome from preconception throughout pregnancy. Hum Reprod 19: 510-521.

60. Glueck CJ, Wang P, Goldenberg N, Sieve-Smith L (2002) Pregnancy outcomes among women with polycystic ovary syndrome treated with metformin. Hum Reprod 17: 2858-2864.

61. Glueck CJ, Bornovali S, Pranikoff J, Goldenberg N, Dharashivkar S, et al (2004) Metformin, pre-eclampsia, and pregnancy outcomes in women with polycystic ovary syndrome. Diabet Med 21: 829-836.

62. Glueck CJ, Goldenberg N, Streicher P, Wang P (2002) The contentious nature of gestational diabetes: diet, insulin, glyburide and metformin. Expert Opin Pharmacother 3: 1557-1568.

63. Glueck CJ, Wang P, Kobayashi S, Phillips H, Sieve-Smith L (2002) Metformin therapy throughout pregnancy reduces the development of gestational diabetes in women with polycystic ovary syndrome. Fertil Steril 77: 520-525.

64. Glueck CJ, Goldenberg N, Streicher P, Wang P (2003) Metformin and gestational diabetes. Curr Diab Rep 3: 303-312.

65. Vanky E, Stridsklev S, Heimstad R, Romundstad P, Skogøy K, et al. (2010) Metformin versus placebo from first trimester to delivery in polycystic ovary syndrome: a randomized, controlled multicenter study. J Clin Endocrinol Metab 95: E448-455

66. Gui J, Liu Q, Feng L (2013) Metformin vs insulin in the management of gestational diabetes: a meta-analysis. PLoS One 8: e64585.

67. Charles B, Norris R, Xiao X, Hague W (2006) Population pharmacokinetics of metformin in late pregnancy. Ther Drug Monit 28: 67-72.

68. Rowan JA, Hague WM, Gao W, Battin MR, Moore MP (2008) Metformin versus insulin for the treatment of gestational diabetes. N Engl J Med 358: 2003-2015.

69. Goh JE, Sadler L, Rowan J (2011) Metformin for gestational diabetes in routine clinical practice. Diabet Med 28: 1082-1087.

70. Chau JF, Lee MK, Law JW, Chung SK, Chung SS (2005) Sodium/myo-inosito cotransporter-1 is essential for the development and function of the peripheral nerves. FASEB J 19: 1887-1889.

71. Dai Z, Chung SK, Miao D, Lau KS, Chan AW, et al. (2011) Sodium/myo-inosito 
Citation: Giugliano E, Cagnazzo E, Giugliano B, Caserta D, Moscarini M, et al. (2013) The Prevention of Gestational Diabetes. J Diabetes Metab 4: 286. doi:10.4172/2155-6156.1000286

cotransporter 1 and myo-inositol are essential for osteogenesis and bone formation. J Bone Miner Res 26: 582-590.

72. Pak Y, Huang LC, Lilley KJ, Larner J (1992) In vivo conversion of $[3 \mathrm{H}]$ myoinositol to [3H]chiroinositol in rat tissues. J Biol Chem 267: 16904-16910.

73. Kennington AS, Hill CR, Craig J, Bogardus C, Raz I, et al. (1990) Low urinary chiro-inositol excretion in non-insulin-dependent diabetes mellitus. $\mathrm{N}$ Engl J Med 323: 373-378

74. Kawa JM, Przybylski R, Taylor CG (2003) Urinary chiro-inositol and myoinositol excretion is elevated in the diabetic $\mathrm{db} / \mathrm{db}$ mouse and streptozotocin diabetic rat. Exp Biol Med (Maywood) 228: 907-914.

75. Olgemöller B, Schwaabe S, Schleicher ED, Gerbitz KD (1993) Upregulation of myo-inositol transport compensates for competitive inhibition by glucose. An explanation for the inositol paradox? Diabetes 42: 1119-1125.

76. Eichberg J, Abe S, Berti-Mattera LN, Day NS, Lowery JM, et al. (1993) Inosito and phospholipid metabolism in diabetic nerve. Diabet Med 10: 16S-20S.

77. Larner J, Craig JW (1996) Urinary myo-inositol-to-chiro-inositol ratios and insulin resistance. Diabetes Care 19: 76-78.

78. Pak Y, Paule CR, Bao YD, Huang LC, Larner J (1993) Insulin stimulates the biosynthesis of chiro-inositol-containing phospholipids in a rat fibroblast line expressing the human insulin receptor. Proc Natl Acad Sci U S A 90: 77597763.

79. Stull AJ, Thyfault JP, Haub MD, Ostlund RE Jr, Campbell WW (2008) Relationships between urinary inositol excretions and whole-body glucose tolerance and skeletal muscle insulin receptor phosphorylation. Metabolism 57: 1545-1551.
80. Dessì A, Atzori L, Noto A, Visser GH, Gazzolo D, et al. (2011) Metabolomics in newborns with intrauterine growth retardation (IUGR): urine reveals markers of metabolic syndrome. J Matern Fetal Neonatal Med 24: 35-39.

81. Genazzani AD, Lanzoni C, Ricchieri F, Jasonni VM (2008) Myo-inosito administration positively affects hyperinsulinemia and hormonal parameters in overweight patients with polycystic ovary syndrome. Gynecol Endocrinol 24 139-144.

82. Papaleo E, Unfer V, Baillargeon JP, De Santis L, Fusi F, et al. (2007) Myoinositol in patients with polycystic ovary syndrome: a novel method for ovulation induction. Gynecol Endocrinol 23: 700-703.

83. Artini PG, Di Berardino OM, Papini F, Genazzani AD, Simi G, et al. (2013) Endocrine and clinical effects of myo-inositol administration in polycystic ovary syndrome. A randomized study. Gynecol Endocrinol 29: 375-379.

84. Gerli S, Papaleo E, Ferrari A, Di Renzo GC (2007) Randomized, double blind placebo-controlled trial: effects of myo-inositol on ovarian function and metabolic factors in women with PCOS. Eur Rev Med Pharmacol Sci 11: 347 354.

85. Costantino D, Minozzi G, Minozzi E, Guaraldi C (2009) Metabolic and hormona effects of myo-inositol in women with polycystic ovary syndrome: a double-blind trial. Eur Rev Med Pharmacol Sci 13: 105-110.

86. Lisi F, Carfagna P, Oliva MM, Rago R, Lisi R, et al. (2012) Pretreatment with myo-inositol in non polycystic ovary syndrome patients undergoing multiple follicular stimulation for IVF: a pilot study. Reprod Biol Endocrinol 10: 52.

87. Ciotta L, Stracquadanio M, Pagano I, Carbonaro A, Palumbo M, et al. (2011) Effects of myo-inositol supplementation on oocyte's quality in PCOS patients: a double blind trial. Eur Rev Med Pharmacol Sci 15: 509-514.
This article was originally published in a special issue, Diabetes: Case Studies handled by Editor(s). Dr. Vishwamitra Sharma, Nottingham University Hospital, UK 